\title{
Migration and Justice: a reply to my critics
}

\author{
David Miller
}

\begin{abstract}
In this response to six critics, I begin by clarifying the sense in which my approach to the issue of immigration is 'realistic'. I also explain why a realistic approach must place immigration in a nationstate context, although without treating it as primarily reparative for historic injustice. I suggest that it is implausible to regard global equality of opportunity, as opposed to global sufficiency, as setting limits to national self-determination. I then defend my use of the distinction between refugees and economic migrants to frame the discussion of immigration against the charge that all migrants are potentially vulnerable to the decisions of admitting states, since these may determine the fate of their life-projects. And I also defend the claim that, in the case of refugees, justice requires only that each state should discharge its fair share of the burden of admitting them; doing more than this would require popular consent. Finally I consider the case of irregular migrants, and explain in what sense they have taken unfair advantage of other potential migrants; I defend offering a conditional amnesty to people in this category.
\end{abstract}

Keywords: amnesty, burden-sharing, economic migrants, equality of opportunity, immigration, irregular migrants, nation-state, realism, refugees, vulnerability.

I should like to begin by thanking the other contributors to this symposium for their generosity on agreeing to discuss my book in a public forum, and for the care they have taken in grappling with my arguments. Insofar as it makes sense to arrange philosophers and political theorists who have written about immigration on a spectrum that runs between 'let them all in' and 'keep them all out', I judge that all the participants stand closer to the first pole than I do, but on the other hand, no-one here tries to defend open borders as a matter of principle. There seems to be a tacit agreement that the interesting questions about immigration are those that arise if we assume that states are going to want to control their borders and limit flows of immigrants; but this leaves many issues about the treatment of immigrants to be resolved, some of which arouse heated controversy among the public at large. As if by an invisible hand, the participants have chosen to focus on different aspects of the book, which however makes it harder to do full justice to their comments in a limited space, and for this I apologise in advance. I will begin with issues of method and approach before moving on to more specific issues of immigration policy.

Several of the symposiasts note that I laud the virtues of realism in writing about immigration from a philosophical perspective. I should clarify that I do not use realism in the semi-technical sense it has taken on in recent debates about method in political philosophy, where it is dismissive of the 
attempt to apply general normative principles, such as principles of justice, to political questions. ${ }^{1}$ The realism I advocate in the book is realism about features of the current world order that have to be taken as given in order to think fruitfully about immigration. ${ }^{2}$ By 'fruitfully' here, I mean in a way that might possibly be of use to a policy-maker having to decide about some aspect of immigration policy. I don't want to suggest that there is nothing to be learned by imagining a world with unhindered freedom of movement - a kind of open-borders News from Nowhere (there could be both libertarian and egalitarian versions of this). But my aim was to sketch the outlines of a legitimate and justifiable immigration policy for a democratic state in the world that we actually inhabit, replete with inequalities and injustices.

Chandran Kukathas suggests that if one starts from that realistic perspective, then there is no need to defend the state's right to control its borders, since states already take that right for granted (subject to certain limitations contained in international law). I think, nonetheless, that there is merit in exploring, positively, what justifies such a right, and negatively, why there is no individual right to unhindered freedom of movement. Finding the best justification (assuming there is one) for imposing border controls will also help us determine the principled limits to the state's exercise of its power. An analogy here would be the justification of (state) punishment. We can take it for granted that states will claim and exercise the right to punish criminals, but that does not mean there is no point in exploring the various justificatory theories that have been proposed - because the one we settle on will have implications for how punishment should be carried out, what penalties it is legitimate to impose, and so forth.

Kukathas is also concerned that I do not prescribe any definite immigration policy for a modern state. But my argument is that this is a matter for democratic decision. It does not make sense to say that each state should take in an equal, or proportional, number of immigrants, for example. Everything depends on the future trajectory that citizens want to follow as they plan their life together - whether to be an expanding high-immigration society like Canada or a more conservative, culturally homogenous society like Japan. The volume and profile of the immigrants unavoidably impacts every other area of public policy - education, housing, the environment, and so forth. The task of the political philosopher here is to explore the values that should inform the democratic decision, and also the principled side-constraints that apply (such as anti-racism).

\footnotetext{
${ }^{1}$ I have tried to clarify my position vis-a-vis realism in this sense in D. Miller, 'In What Sense must Political Philosophy be Political?', Social Philosophy and Policy, forthcoming.

${ }^{2}$ Thanks to Phil Parvin's excellent introduction to this symposium, I need not expand on this point any further here.
} 
Sarah Fine, too, approves of my attempt to be realistic, but she thinks that my starting point is not realistic enough, in particular because it relies too heavily on a stylised view of the homogenous nation-state as the reference point for a discussion of immigration. She calls the idea of the national community 'one of politics' greatest fictions'. But if it is a fiction, it is one with powerful teeth. Time and again, ambitious plans for world government and other forms of international order have crumbled as people reassert their commitment to national self-determination. Just now, we may be witnessing the first stages in the dissolution of the European Union, as national sentiment erupts again. The point about the nation-state is not that at any one moment every citizen identifies in the same way with national culture or national history, but that it contains mechanisms that over time operate to create a common frame of reference - and one into which immigrants are expected to fit. I agree that there are countertendencies at work: the increasing popularity of dual citizenship, the rise of global media that create new, non-territorial, forms of political identity, and so on. Maybe these will eventually win out. But meanwhile it makes sense to assume that immigration means entering a state whose members, despite their political differences, see themselves as belonging to a political community with a distinct culture and historical roots. How can we begin to think about the cultural challenges that immigration poses if we don't begin with that assumption? Fine also charges that in my depiction of the nation-state as a political community with historic roots, I leave out all the negative aspects of that history - colonialism, slave trading, and so forth. I have defended elsewhere the idea that nations may have remedial responsibilities for the historical injustices that their members have committed. ${ }^{3}$ The question is how, if at all, this bears on immigration policy. Why should granting some individuals the right to immigrate be the best or most appropriate way of rectifying injustices that have been inflicted on whole societies? It seems that in nearly every case redress, whether it takes the form of restitution or compensation, should be provided collectively to the community that has suffered the wrong. The exceptional cases are those in which particular people are put at risk by actions that the state has taken - for example an Iraqi who worked with coalition forces during the second Gulf War and finds his life endangered as a result. Such a person has a strong reparative claim which should push him to the front of the refugee line. But allowing reparative concerns to dominate immigration policy as a whole would in my view be a backward step. On the one hand, if reparation plays a large role in determining who is to be granted asylum, this may work to the detriment of other refugees whose rights are under greater threat. If we have to choose, shouldn't we choose those whose human rights are most immediately and seriously at risk, regardless of whether we have played a causal role in bringing

\footnotetext{
${ }^{3}$ D. Miller, National Responsibility and Global Justice (Oxford: Oxford University Press, 2007), ch. 6.
} 
about their current condition? On the other hand, with migrants in general, it is surely better to emphasize the positive contribution they are going to make to the host society as the ground for admitting them than to portray them as victims to whom compensation is owed for ancestral wrongs.

My appeal to national self-determination as a value that should condition immigration policy is challenged by Esther Kollar who, while not denying that self-determination is valuable, argues that it needs to be checked by global justice principles. Nations, she says, 'just like families, should not be permitted to transmit unlimited advantages to their members'. This is correct if what she means is that they should not transmit advantages that require exploiting people in foreign countries, or making them worse off by other means. But it would be very odd to suggest that we should refrain from improving citizens' lives by protecting the environment, investing in the arts, building better transport systems and so forth simply out of a concern that we might be making them better off relative to people who live elsewhere. This seems, however, to be what Kollar is proposing.

Kollar suggests that my critique of global equality of opportunity depends on giving that principle a strong, radical interpretation. Instead, she argues, what justice requires is that we should mitigate, not abolish, inequalities in people's life-chances world-wide. Using the language of mitigation here might be confusing, however. Kollar's meaning is not that, having identified global inequalities in opportunity, we are only required as a matter of justice to reduce them partially, not eliminate them altogether. Instead, she means that we should nullify the effects of only some of the 'morally arbitrary' factors that produce global inequality. The analogy is supposed to be with Rawls' interpretation of fair equality of opportunity at domestic level, where the causal effects of the family on the opportunities of the rising generation are discounted. ${ }^{4}$ The justification for the discounting is the value that is realised by allowing parents and children to interact in certain ways. Moving to the international case, the analogue to the family is the self-determining political community, and the inegalitarian effects of its decisions. So Kollar suggests that we have first to identify the value that is realised through collective self-determination, and this will also establish the limits within which it may legitimately be exercised.

\footnotetext{
${ }^{4}$ In fact, Rawls is ambiguous about this. He wavers between saying that equality of opportunity can't be fully achieved so long as the institution of the family exists, and saying that familyinfluenced differences in motivation and capacity to gain from education are consistent with fair equality of opportunity as he defines it. See my discussion in 'Equality of Opportunity and the Family' in D. Miller, Justice for Earthlings; essays in political philosophy (Cambridge: Cambridge University Press, 2013).
} 
I find it hard to make sense of this suggestion. If political self-determination is valuable, it is valuable across all areas of policy. Some of these are of course more important than others: people are likely to care more about democratic control of economic or health policy than about policy towards the arts, for example. But these are also the policy areas in which inequalities of outcome are most likely to trouble global egalitarians. So if we try to impose constraints on self-determination in these domains in the name of global equality of opportunity, self-determination is going to be taking a very big hit. It is hard to believe that citizens could find value in deciding for themselves only in areas which had no significant material consequences for inequality, like choosing the design of the national flag.

In support of the idea of mitigating as opposed to eliminating global inequalities, Kollar offers the example of a Sierra Leonean child whose life expectancy is only half that of a child born in the UK as an inequality that cannot be excused by appeal to national self-determination. But what is striking about this example is that it derives its force not from any intuitions we might have about global inequality but about the indecency of people having a life expectancy of only 41 years. Few would think it an improvement from the point of justice if life expectancy in the UK were also to be reduced to 41 years. The moral to be drawn is surely not that the UK should be disabled from exercising selfdetermination in those policy areas, such as public health, that have produced longevity for its citizens, but that it stands under an obligation of justice to help create conditions in which life expectancy in Sierra Leone will increase - for example by sharing medical expertise and technology. The argument is no longer about inequality as such, but about setting a global social minimum and requiring rich states to contribute to achieving it.

My discussion of immigration policy in the second half of the book relies on the distinction between economic migrants and refugees, which is challenged most directly by Sarah Fine, who finds the very term 'economic migrant' problematic (but how else should we describe someone like Mark Carney who moves from being Governor of the Bank of Canada to being Governor of the Bank of England?). Although she does not spell this out, I take her to be saying that no real distinction can be drawn between refugees and other migrants, since everyone who moves across borders has good reasons for doing so. But making this move is a mistake, and one that is liable to backfire on those who try to assert the absence of a distinction as a way of justifying having more open borders. If there is no real distinction, then we can equally well say that refugees are just economic migrants under another name - something many people are only too ready to believe. We need to avoid such a conceptual collapse. Our moral relationship to refugees is different from our relationship to migrants in general, and this should also make a big difference to how we respond to their claims in practice. 
Christine Straehle enlarges upon my suggestion that we can understand the relationship between a refugee and the state she applies to for asylum as one of vulnerability. My thought was that by lodging her asylum claim, the refugee becomes almost wholly reliant on one particular state to protect her basic rights, and this gives rise to a specific obligation of care on the part of that state. Straehle develops this by arguing that migrants more generally have life projects that can only be fulfilled by moving to a particular state and this is what makes them vulnerable to the state's decision whether to admit them or not. However this seems to me to open the door very wide, and to risk a certain kind of arbitrariness in the way that admission decisions would be made. The unlucky admissions officer in state S would need to decide, in the case of each applicant, whether his life-project was such that it could only be realised in $S$, or whether he had would have sufficient opportunities elsewhere. There would be an incentive to tailor life-projects to particular countries ('It's not just folk music that I want to make my life's study, but English folk music'). Vulnerability in this extended sense does not carry the same moral punch as it does in cases where basic rights are at stake. Squire Boldwood, Sergeant Troy and Gabriel Oak are all vulnerable to Bathsheba Everdene's decision about whom she should marry, but this does not create any special obligations on her part towards them.

Of course when we refuse people things that they can (reasonably) ask of us, we owe them a reason for the refusal. Bathsheba owes her unsuccessful suitors a polite explanation of why she cannot or will not marry them. Returning to the case of immigration, my weak cosmopolitanism entails (as Straehle notes) that a state must provide reasons to the would-be migrants to whom it denies admission. But these reasons do not have to be person-specific: they can, for example, take the form of an immigration policy based on a points system which gives an applicant credit for the qualifications and other features she may have, with an accompanying rationale. The reason for refusal is then simply 'your score is too low, according to our rules'. Straehle appears to believe that it is problematic to compromise someone's autonomy by denying them one of the conditions necessary for them to carry out their life project. But in fact this is something that happens quite routinely within domestic society. Every time a student is turned down for university admission or an actor is denied the plum part that would launch his career, autonomy in Straehle's senses is potentially compromised: the rejected candidate may have to abandon her original aspirations and settle on an alternative life-path. A normatively relevant concept of autonomy cannot tie it to success in the particular life-project that someone has chosen.

Does it make a difference, though, that immigration controls prevent those denied entry from carrying out their life-projects, in cases where these projects can only be realised by moving to a particular country? In other words, is there a difference between an option simply not being 
available to someone, and its being denied them by virtue of a coercively-enforced rule such as an immigration law? Referring to the work of Kieran Oberman, Straehle suggest that it does make a difference. But return to the domestic examples in the previous paragraph. Consider the student who is refused admission to the university of his choice. What happens if he nevertheless turns up and demands to be allowed to attend lectures and contribute to seminars? At some point, presumably, the police will be called in to remove him from the campus. The university has an admissions policy which it should be prepared to enforce. The same applies to the disappointed actor. If he appears at rehearsal and tries to speak some of Hamlet's lines, the theatre will have to take steps to remove him from the premises. I don't believe Straehle would find these cases problematic. So why is immigration policy different? The difference might seem to be that no-one is harmed by admitting one extra immigrant, whereas prevention in the domestic cases can be justified by pointing to the interests of other people involved - fellow students and fellow thespians. But this involves a fallacy of composition. Terrorists, psychopaths and career criminals aside, it is true that admitting any single immigrant will not have detectable harmful consequences. But immigration policy is concerned with the aggregate effects of admitting large numbers of people with specified characteristics. Once a defensible policy has been established, it must for obvious reasons be applied in individual cases.

I have so far defended the distinction between refugees and economic migrants against the claim that the reasons the former have for seeking admission can be extended to the latter as well. But who should we count as a refugee? In the book, I define a refugee as someone who is forced to leave her country of residence because there is no feasible way for her human rights to be protected so long as she remains inside, and David Owen pursues some of the implications of this definition, which is wider than the legal one contained in the Geneva Convention. He suggests first that refugees have a valid claim to be put on an accelerated path to citizenship in the country that hosts them. However the widened definition that I favour is meant to embrace the large numbers of people who are not fleeing persecution as such, by escaping from civil war or state breakdown, and for these people refugee status ought normally to be regarded as time-limited. The expectation is that the disaster they are escaping will come to an end, at which point they should be encouraged to return to help rebuild their society (this may be recognized by giving them 'temporary protected status' (US) or 'discretionary leave to remain' (UK) rather than designating them as refugees). Offering a fast track to citizenship would create the wrong incentives for this group. This is not to disallow permanent refugee resettlement in cases where it can be shown that the person in question has special needs or is very unlikely to be able to live decently in her home society in the future. I endorse Owen's concerns about the risks of cherry-picking when resettlement is being 
offered, though I note that the injustice that this may involve is not injustice toward the refugees themselves, but injustice towards the state that currently houses them.

The bigger issue that divides us, as Owen points out, concerns the nature and extent of our obligation, as citizens of a particular state, to shelter refugees. Owen accepts that there might be extreme cases in which a state had to choose between protecting the rights of refugees and protecting the rights of its own citizens, in which case it could (should?) legitimately favour the latter. He also appears to accept the idea of creating a burden-sharing scheme, with each state being placed under a duty to accommodate its fair share of refugees. But he argues that there is a (tertiary) duty of justice, not merely a humanitarian duty, to take in more than that fair share if other states default on their obligations under the scheme.

I have set out elsewhere the general reasons for thinking that there is no duty of justice to take up the slack in circumstances where other agents refuse to take on their fair share of a common task, and there is no space here to rehearse those reasons. ${ }^{5}$ What I should like to underline now is why it matters whether we see the additional duty created by non-compliance as a duty of justice or a duty of humanity (it might otherwise just seem to be a case of philosophical nit-picking). It matters first because duties of humanity are not enforceable, which means that no outside agency could coerce a state into taking more refugees than it was required to take under a burden-sharing scheme. It also matters internally, because a decision to act on a humanitarian obligation requires the consent of the people upon whom the costs of discharging the obligation are going to fall. So if, as seems plausible, Angela Merkel was committing Germany to doing more than its fair share of refugee protection within Europe when she announced in 2015 that her country would be willing to take in all those who arrived at its borders, she was acting unilaterally in a way that exceeded her legitimate authority. Her decision needed democratic endorsement.

Owen asks a further question, about what refugees to whom no state is willing to offer protection may do to secure their human rights. Let's consider first the case where a burden-sharing scheme has been created under which, if every participating state complied with its obligations, all refugees would be safely housed somewhere. In the event of non-compliance by some states, excluded refugees have a claim of justice against the defaulters, and may legitimately try to gain access to their territory; they may not, however, attempt to exercise their rights against states that have already done their fair share. But now consider the more extreme case where the demand for protection exceeds the capacity of all states taken together to supply it. Here the refugee has a right

\footnotetext{
${ }^{5}$ D. Miller, 'Taking up the Slack? Responsibility and justice in situations of partial compliance' in Miller, Justice for Earthlings.
} 
of self-preservation, and the state, acting on behalf of its citizens, has the right to protect the latter from invasion. We may hope and pray that this quasi-Hobbesian situation does not arise, but if it does we find ourselves in a place where neither party has a claim-right to the other's acquiescence. The refugee may use morally permissible means to try to enter, and the state may use morally permissible means to try to prevent him. The two parties are effectively in a state of war, and are subject only to constraints of the kind that we find in the law of armed conflict.

Returning to calmer waters, Owen challenges some aspects of my treatment of temporary migration schemes. Having initially been drawn to Michaels Walzer's view that with few exceptions such schemes were incompatible with the ground rules of a democratic society, I was persuaded that they could make an important contribution to the economic development of poor countries, via remittances and the skills that returning migrants might bring with them. So there is a straightforward trade-off in values here: preserving full political equality within liberal democracies versus helping to alleviate global poverty. As always there is a temptation to think one can have one's cake and eat it, by progressively improving the material position of temporary workers and granting them more rights. But unfortunately this can have detrimental effects, either by making employers less likely to hire temporary migrants, or by reducing the probability that they will continue to send back substantial remittances as time passes. My proposal was to set a floor sufficiently high to prevent exploitation, but not to guarantee short-term migrants fully equal treatment in the workplace or to grant rights of permanent residence and access to citizenship. Owen highlights the importance of the norm of equal pay for equal work. I agree that this is an important norm, but it is subject to qualifications. We don't, for example, insist on it in the case of apprentices or interns who may happen to be doing the same thing at work as their seniors. In the case of temporary migrants, it is relevant that they are likely to have lower costs to set against their wage, since part of it will be used to support dependents in countries where living is cheaper. And I think that such schemes should have short fixed terms - one or two years - with limited opportunities for renewal (there should of course be no barrier to someone who has held temporary status subsequently applying through normal immigration channels). The aim is to ensure that all three parties - the host country, the migrant, and her home society - derive a fair share of the gains created by the scheme.

I turn finally to Oliviero Angeli's discussion of the claims of irregular migrants. He starts by disputing my claim that such people have acted wrongly by evading the state's immigration laws. He questions whether it can be shown that they have a duty to comply with these laws, since their interests are not weighed equally with those of existing citizens when the laws are being made - the latter benefit from compatriot partiality. It does not seem, however, that duties are only valid if 
they pass an interest-balancing test of this kind in each particular case. We think, for example, that my neighbour has a duty not to reach over the fence and pick an apple from my tree without asking me first, even if it is true that he would derive far more benefit from eating the apple than I would. The law of property protects my interests and largely ignores his, but the institution as a whole can be justified to us both. Returning to the immigration case, the question is whether the rules that govern border-crossing can be given a general justification, not whether they can be shown to advance the interests of individual persons equally. As I have indicated earlier, the resulting duties may not apply in cases where the migrant is escaping a life-threatening situation. But Angeli is considering the more general case in which a migrant moves illegally in search of a better life.

One may still wonder in what sense such migrants can be accused of having acted unfairly. Angeli asks whether irregular immigration is 'an immoral act'. 'Immoral' is certainly a bit strong here. An analogy might be drawn with shoplifting. The shoplifter acts wrongly, in normal cases, because the effect of her actions is to make the stores she frequents raise the prices they charge to honest customers to cover their losses - but there also circumstances in which the wrong is excusable. The effect of illegal immigration is to reduce the number of legal migrants who will be admitted, since the labour market has become crowded - so the behaviour of the irregulars disadvantages people waiting patiently in the queue for admission (to suggest otherwise is to suppose that states are not responding to labour market conditions when they set immigration quotas - but they plainly are). Taking advantage in this way is also wrong, but potentially excusable in cases where the migrant is escaping dire poverty.

With respect to irregular migrants who have already arrived, the question is whether they should be allowed to advance towards full citizenship in the same way as other immigrants. This will depend on the length of time for which they have been present. In the book, I join those who argue in favour of a conditional amnesty which requires the irregular to perform a period of part-time public service to rectify his position. Sarah Fine suggests that this proposal will attract controversy, but the benefit to the migrant herself of having her position regularised is so great that it looks like a good bargain overall. Opposition to making amnesty conditional in this way tacitly presupposes, I think, that there was never any justification for keeping the migrants out - a good illustration of the way that where one stands on the fundamental question of the respective rights of states and immigrants influences how one answers policy questions.

There are understandable reasons, some philosophical, some sociological, why academics who write about immigration nearly all end up arguing for looser border controls and more favourable treatment of the immigrants who arrive. From this perspective, it may be hard to understand why 
opposition to mass immigration is so strong among the general public, and tempting to dismiss such opposition as driven by simple xenophobia. One of the main aims of my book is to show that there is a principled argument for a somewhat restrictive immigration policy, grounded in the values that underpin the democratic welfare state. The most coherent arguments for opening borders are those that, like Kukathas's, begin from libertarian or classical liberal premises. What I find most surprising about the current immigration debate is the extent to which those on the egalitarian left unthinkingly assume that it is 'progressive' to be pro-immigration, regardless of the impact that mass migration has on the societies that the migrants leave and those they join. My hope is that Strangers in our Midst will arouse a few of these at least from their dogmatic slumber. 